\title{
DISPOSITIVO DE CAMINHADA: VALIE REPLACEMENT
}

Patricia Teles Sobreira de Souza ${ }^{1}$ 


\section{Resumo}

Valie Replacement (2017) consiste em uma série de colagens realizadas a partir de obras pictóricas renomadas que representam figuras femininas. Pensando na dicotomia da representação da mulher nas artes, objeto $x$ sujeito, o trabalho propõe justapor sobre os corpos das mulheres pintadas uma imagem icônica da artista Valie Export. As colagens podem ser impressas em folha de ofício e distribuídas como um dispositivo de caminhada, um objeto que opera como um propositor de deslocamento. Nesta ação, a pessoa que receber o cartaz será instruída a caminhar em busca de um local para fixá-lo (um poste, um orelhão, um ponto de ônibus, uma lixeira, etc.). O trabalho foi desenvolvido no âmbito da disciplina Tópicos em Poéticas Contemporâneas 2: Poéticas da Caminhada e do Deslocamento - Programa de Pós-graduação em Arte (PPG-ARTE/UnB) - ministrada pela Profa. Dra. Nivalda Assunção.

Palavras-chave: Dispositivo de caminhada. Valie Export. Colagem. Feminismo. Lambe-lambe.

ISSN: 2175-2346 


\section{Dispositivo de Caminhada: Valie Replacement}

Dispositivo de Caminhada: Valie Replacement consiste em uma série composta por seis colagens digitais, realizadas por meio da apropriação artística de obras pictóricas renomadas e das célebres fotografias da ação Action Pants: Genital Panic (1969) da artista feminista Valie Export. Para realizar a colagem, as figuras femininas retratadas nos quadros foram sobrepostas pela imagem da performer austríaca. Por meio da apropriação e justaposição de imagens de distintos períodos da historia da arte, busca-se conferir ao trabalho um caráter iconoclasta e refletir sobre a representação da mulher na esfera artística.

A representação da figura feminina foi o critério de seleção dos quadros, são eles: O Casal Arnolfini (1434) de Jan van Eyck, O Nascimento de Vênus (1484-1486) de Sandro Botticelli, A Vênus Adormecida (1507-1510) de Giorgione e Ticiano, A Liberdade guiando o povo (1830) de Eugène Delacroix, O Almoço na Relva (18621863) de Édouard Manet e O Descanso da Modelo (1882) de Almeida Júnior. Com base nos quadros, as colagens da série Valie Replacement (2017) foram intituladas: O Casal Export, O Nascimento de Valie, Valie Adormecida, Valie guiando o povo, 0 Almoço de Valie e O Descanso de Valie.

Valie Replacement foi desenvolvido no âmbito da disciplina Tópicos em Poéticas Contemporâneas 2: Poéticas da Caminhada e do Deslocamento, ministrada pela Profa. Dra. Nivalda Assunção no Programa de Pós-graduação em Arte da Universidade de Brasília. O projeto partiu de um sorteio de dois artistas que realizam trabalhos vinculados à questão da caminhada como prática artística. As artistas sorteadas como referentes artísticos foram: Valie Export e Janine Antoni.

Valie Export (1940 - ) é uma artista austríaca que utiliza seu corpo para realizar ações que discorrem acerca da representação do feminino e da dominação masculina. Em From the Portfolio of Dogness (1968) Valie caminhou guiando seu parceiro, o artista Peter Weibel, como se fosse um cachorro. Com o pescoço preso a uma coleira e com os joelhos e mãos apoiados no chão, Weibel era conduzido por Valie. Um ano depois, em Action Pants: Genital Panic - descabelada, vestida com uma jaqueta de couro, uma calça jeans rasgada na altura da virilha e portando uma arma de fogo - Valie entrou em um cinema de Munique confrontando os espectadores com sua vagina exposta e sua presença tangível, em oposição as imagens das mulheres projetadas na telas de cinema.

Janine Antoni (1964 - ) é uma artista bahamense que reside em Nova York e, assim como Valie Export, sua produção artística é reconhecida, entre outros fatores, pelo caráter feminista. Em 1993 Antoni realizou a performance Loving Care, na qual a artista pinta o chão com os cabelos. A ação foi criticada pelo historiador de arte Benjamin Buchloh que afirmou se tratar de uma "espetacularização da teoria feminista" e uma variação da performance Vagina Painting (1965) da artista do Fluxus, Shigeko Kubota (MIYOSHI, 2011, p.135).

Contudo, segundo Miyoshi (2011, p.136), além da critica a obra Sinfonia Monotônica (1949) de Yves Klein, Janine evoca os "inúmeros quadros oitocentistas representando mulheres sonolentas ou mortas sobre superfícies úmidas, com os cabelos 
longos e esparramados..." contrapondo a imobilidade com corpo enérgico. Portanto, o trabalho fundamenta-se na convergência temática entre as artistas sorteadas, ambas realizam ações que refletem sobre a questão da mulher na sociedade e nas artes.

Os cartazes lambe-lambe foram criados para serem distribuídos pela cidade (pontos de ônibus, lixeiras, postes, paredes, telefones públicos, entre outros). Portanto, a poética da caminhada em Valie Replacement é abordada por meio dos participantes, que devem caminhar e observar o entorno para escolher um ponto para fixação das imagens. Deste modo, o cartaz se configura como um dispositivo de caminhada, um objeto que opera como propositor/gerador do deslocamento dos participantes. 
1. recorte as imagens; 2 . reserve um tubo de cola; 3 . caminhe até encontrar um ponto para fixá-las.

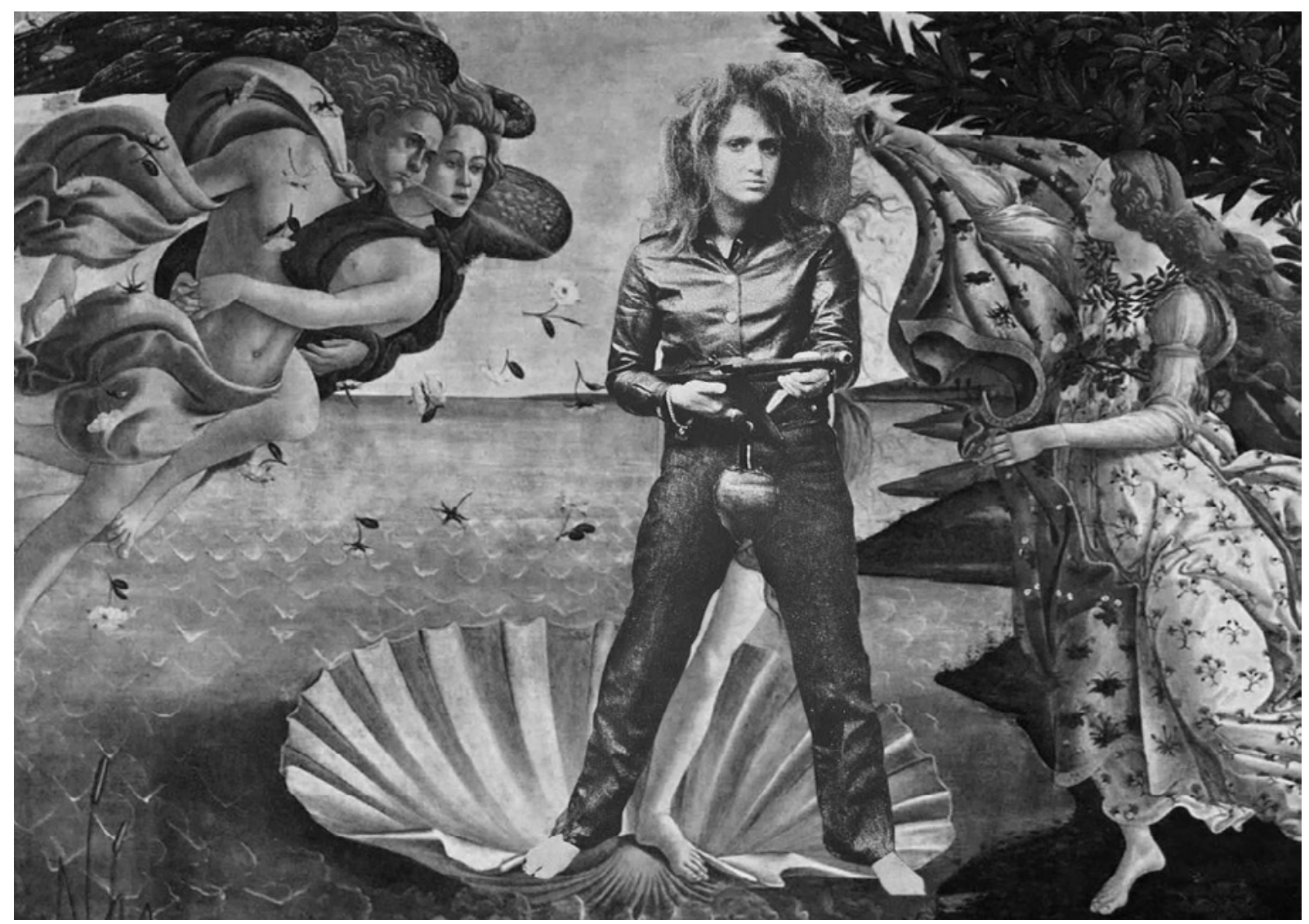

O Nascimento de Valie (2017).

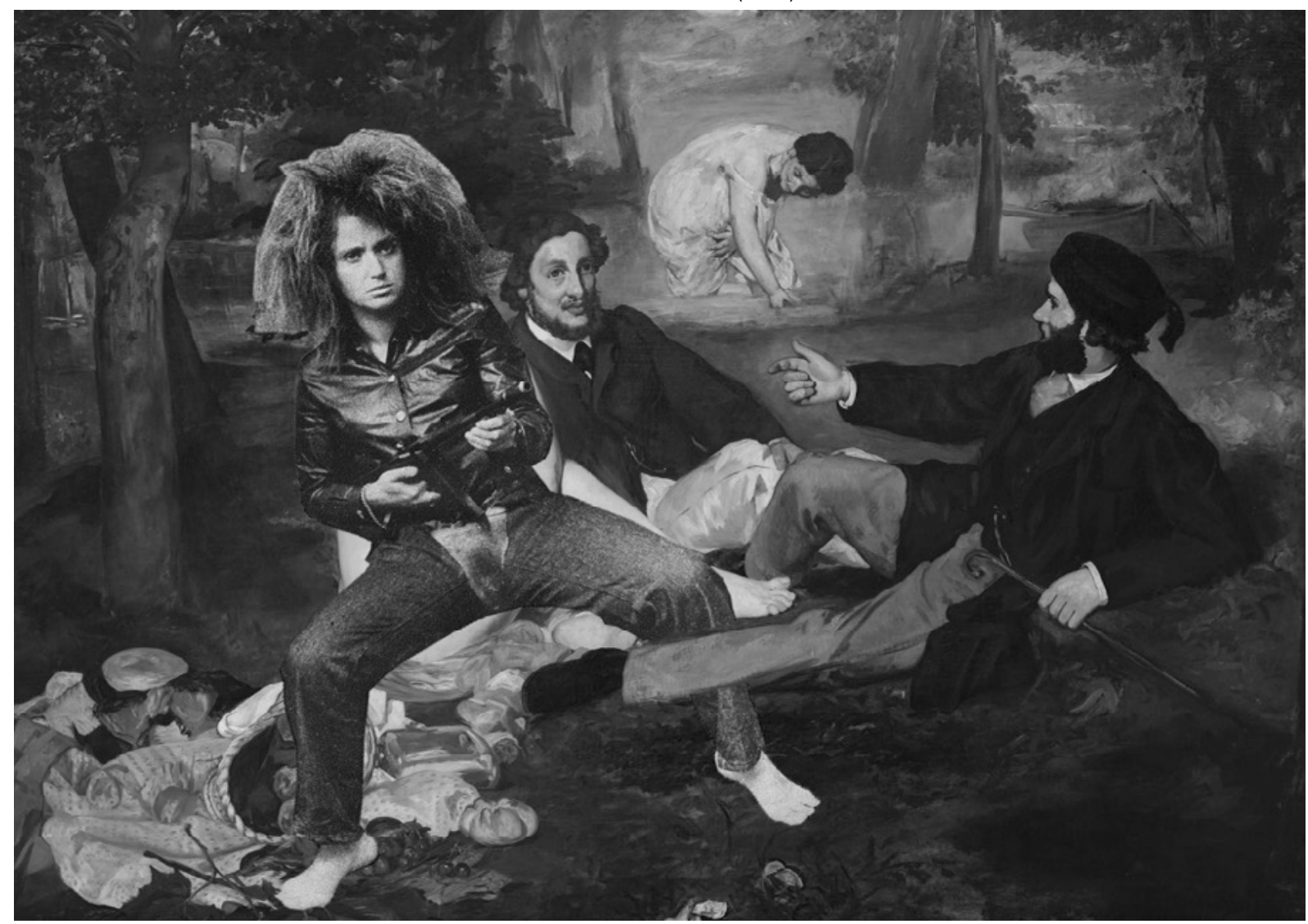

O Almoço de Valie (2017). 


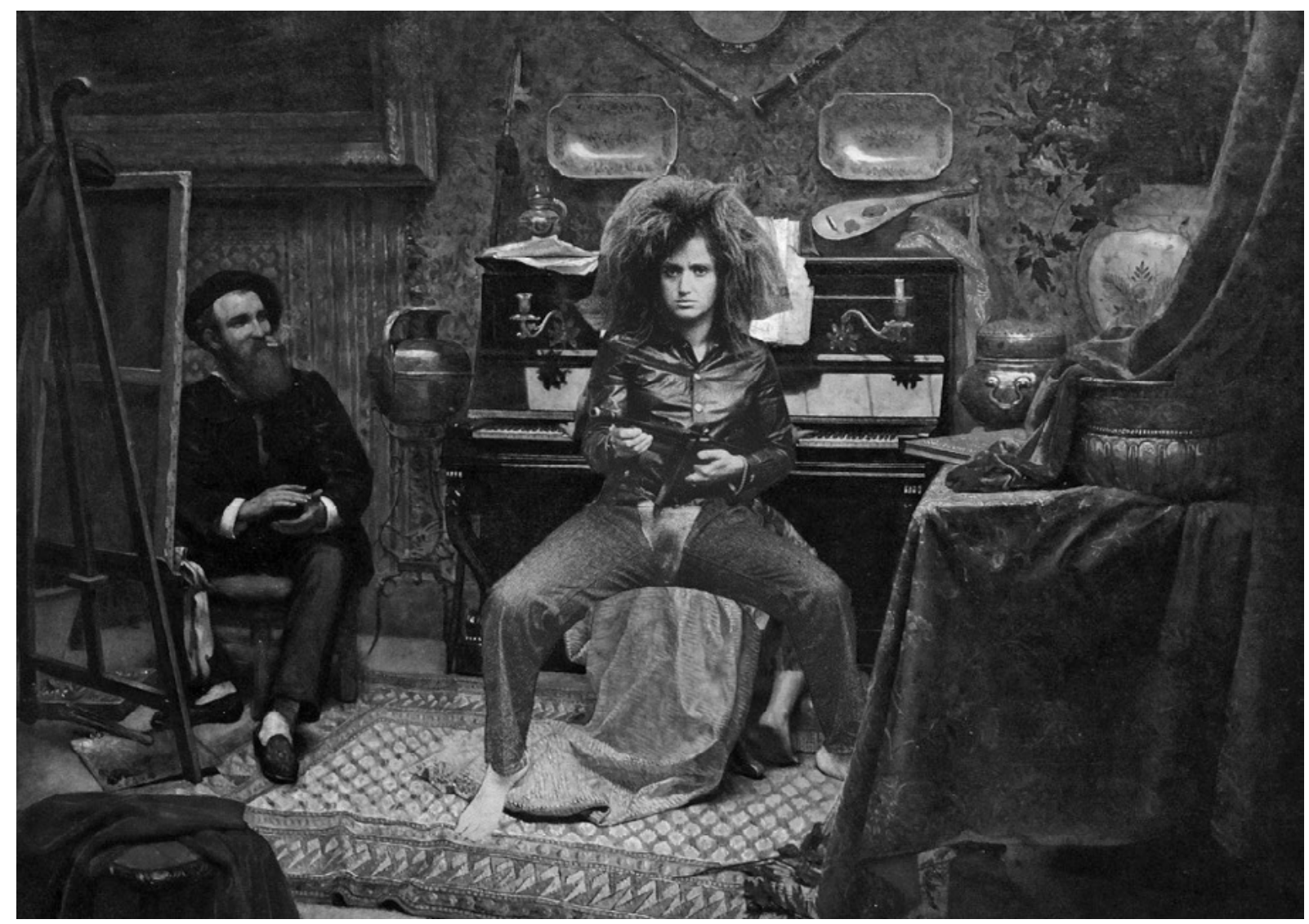

O Descanso de Valie (2017).

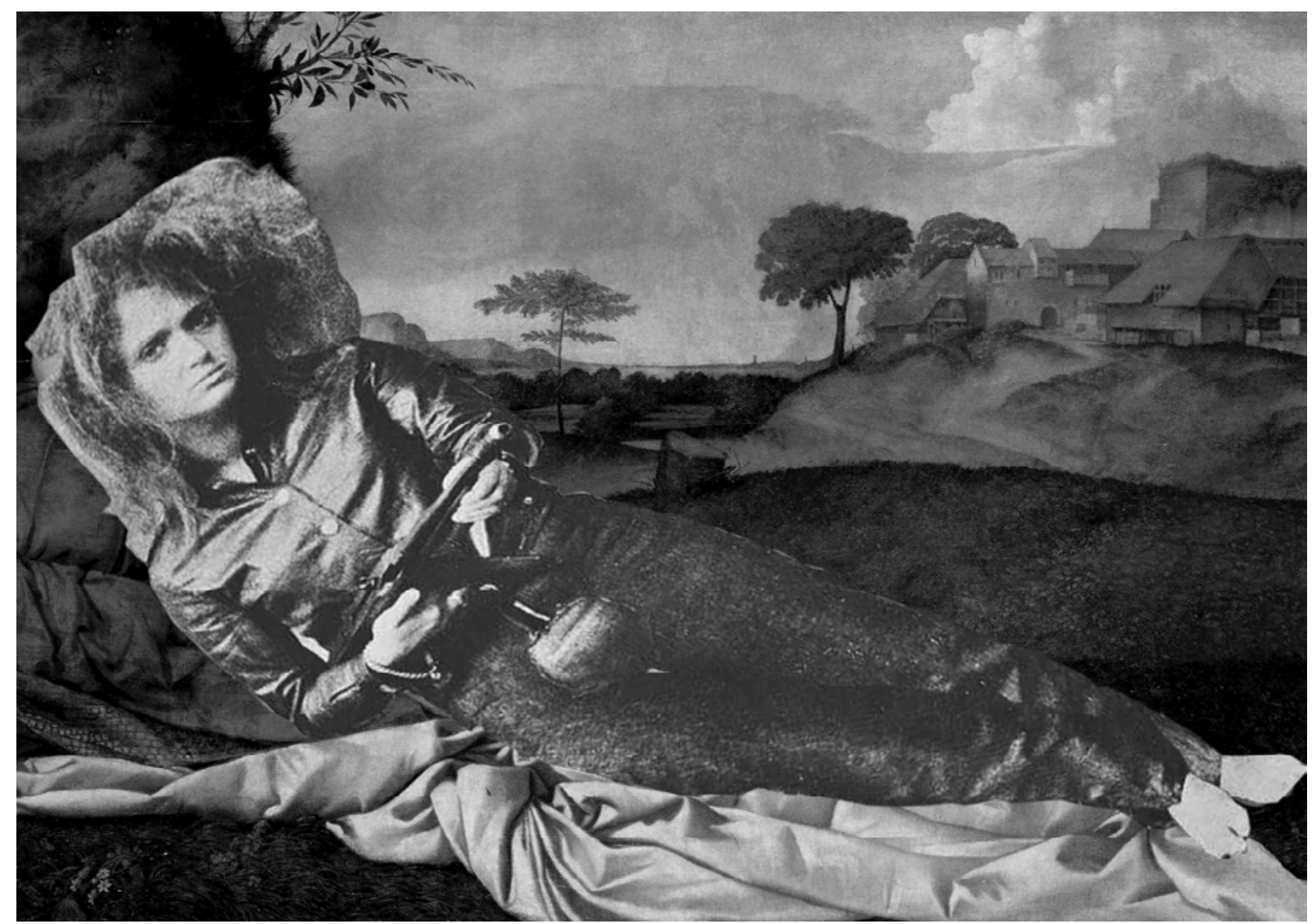

Valie Adormecida (2017). 


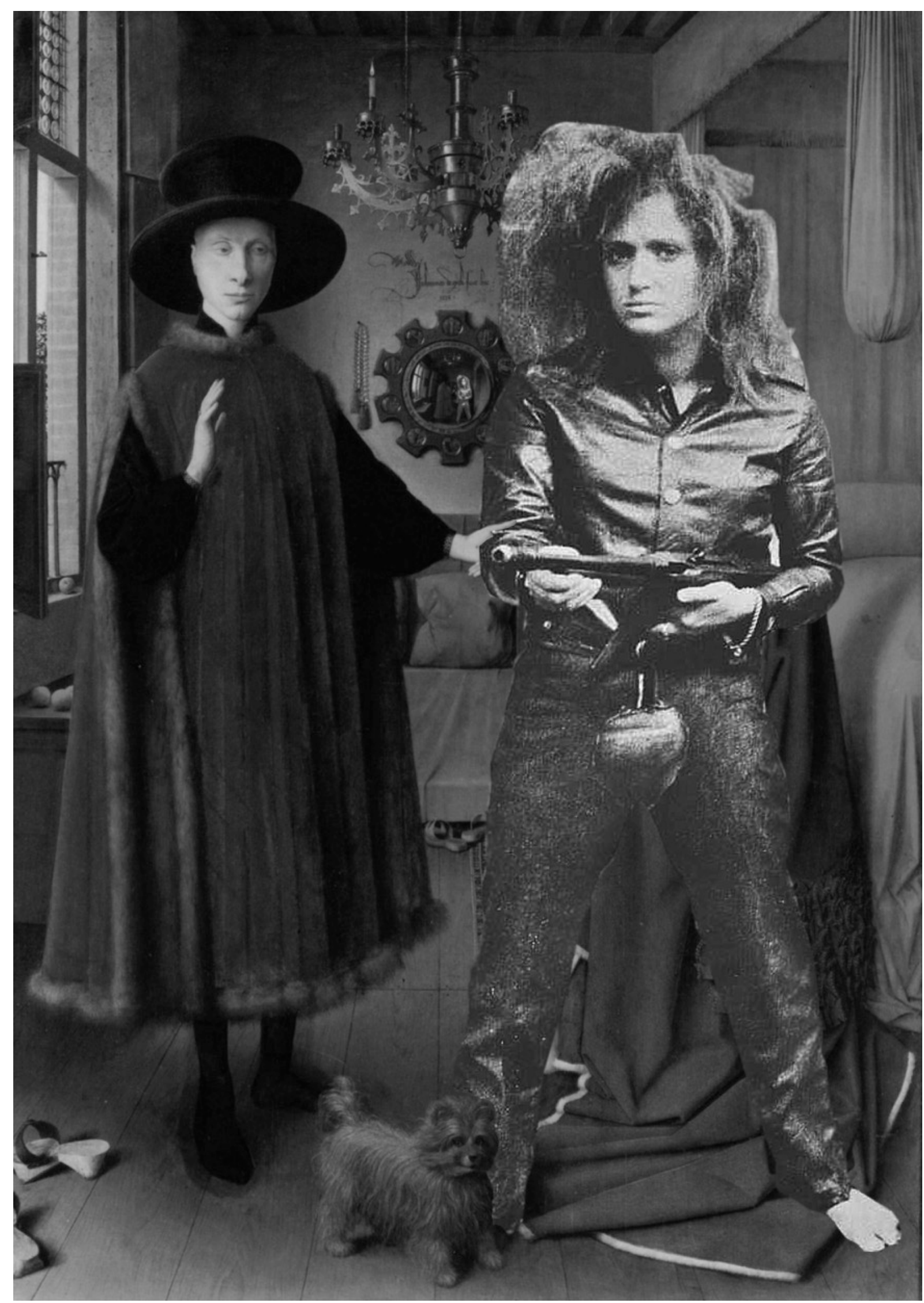

O Casal Export (2017). 


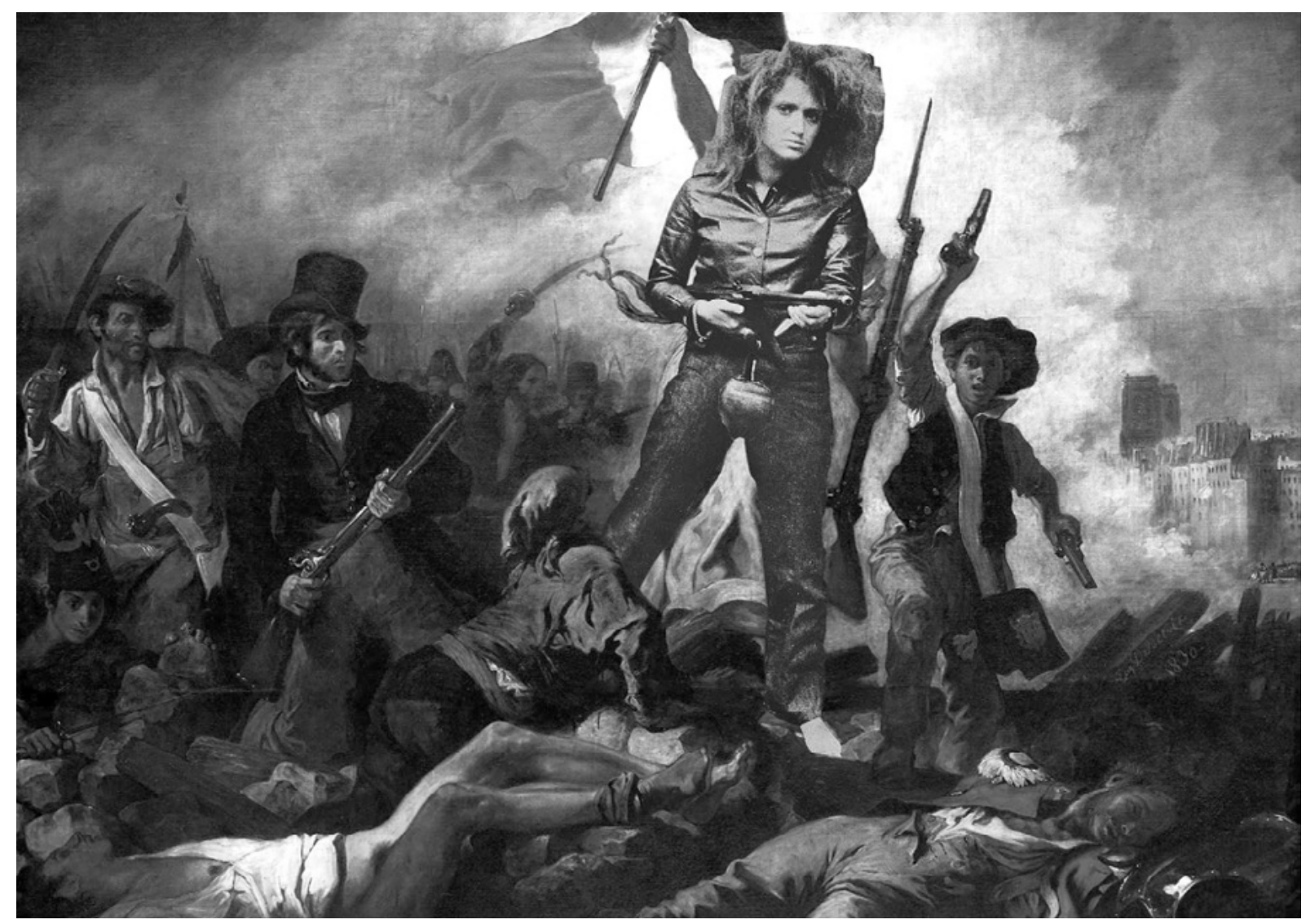

Valie guiando o povo (2017).

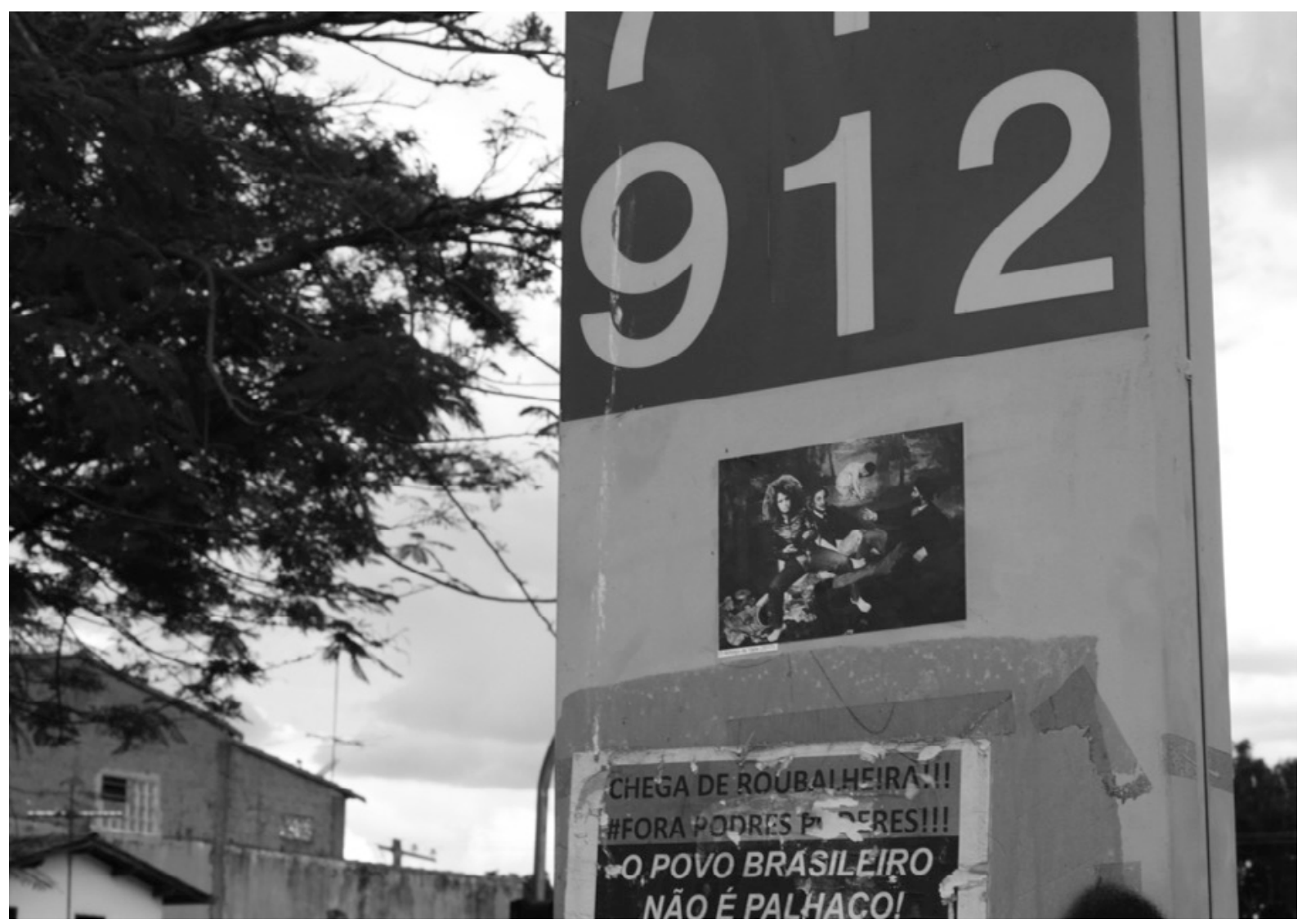

Registro 1 - Brasília, 6 novembro de 2017. 


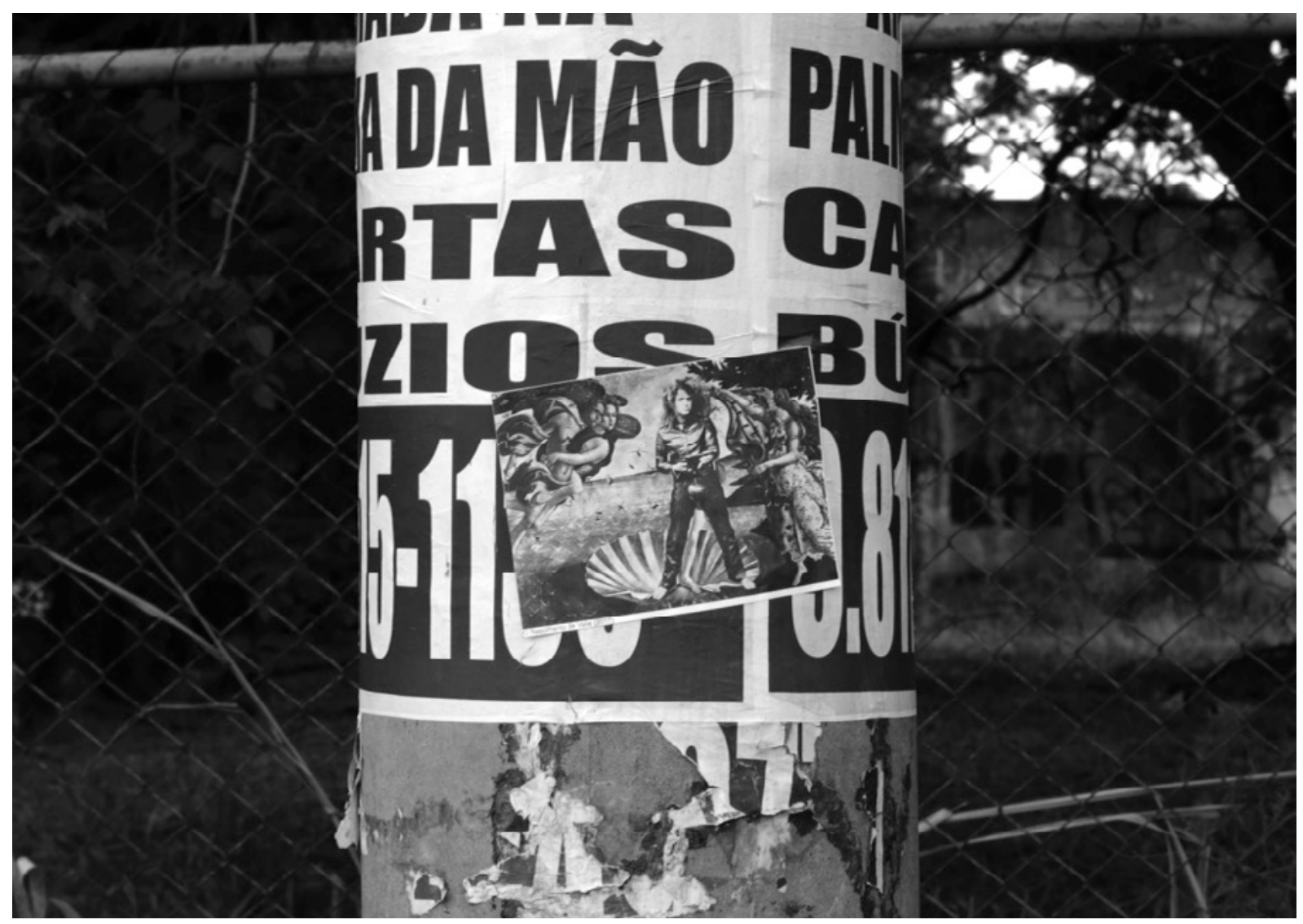

Registro 2 - Brasília, 6 de novembro de 2017.

\section{Referências}

MIYOSHI, A. Janine Antoni e a história da arte. Revista da História da Arte e Arqueologia, UNICAMP, n.15, 2011, p.133-144. 